\title{
Influence of the hydrophilic surface of nanofiber support on the performance of hybrid supercapacitors
}

\author{
Hyo-Young Kim ${ }^{1,2,+}$, Seon-Yeong Lee ${ }^{1,+}$, In-Yup Jeon ${ }^{1,3,{ }^{*}}$, Jeeyoung Shin ${ }^{4,5,{ }^{*},}$, Young-Wan Ju ${ }^{1,3, *}$ \\ ${ }^{1}$ Department of Chemical Engineering, College of Engineering, Wonkwang University, Iksan, Jeonbuk 54538, \\ Republic of Korea \\ ${ }^{2}$ Department of Automotive science, Facility of Integrated Frontier Sciences, Kyushu University, Fukuoka, \\ 813-8503, Japan \\ ${ }^{3}$ Nanoscale Sciences and Technology Institute, Wonkwang University, Iksan, Jeonbuk 54538, Republic of Ko- \\ rea \\ ${ }^{4}$ Department of Mechanical Systems Engineering, Sookmyung Women's University, Seoul 04310, Korea \\ ${ }^{5}$ Institute of Advanced Materials and Systems, Sookmyung Women's University, Seoul 04310, Korea \\ + These authors contributed equally to this work \\ *Corresponding author: ywju1978@wku.ac.kr (Y.-W.J.); jshin@sookmyung.ac.kr (J.S); iyjeon79@wku.ac.kr \\ (I.Y.J)
}

\begin{abstract}
Concerns associated with global warming and the depleting reserves of fossil fuels have highlighted the importance of high-performance energy storage systems (ESSs) for efficient energy usage. ESSs such as supercapacitors can contribute to improved power quality of an energy generation system, which is characterized by a slow load response. Composite materials are primarily used as supercapacitor electrodes because they can compensate for the disadvantages of carbon or metal oxide electrode materials. In this study, a composite of oxide nanoparticles loaded on a carbon nanofiber support was used as an electrode material for a hybrid supercapacitor. The addition of a small amount of hydrophobic Fe- and N-doped graphene nanoplates modified the surface properties of carbon nanofibers prepared by electrospinning. Accordingly, the effects of the hydropho$\mathrm{bic} /$ hydrophilic surface properties of the nanofiber support on the morphology of $\mathrm{Co}_{3} \mathrm{O}_{4}$ nanoparticles loaded on the nanofiber, as well as the performance of the supercapacitor, were systematically investigated.
\end{abstract}

Keywords: Composite electrode, Nanofiber support, Hydrophobic/hydrophilic properties, Dispersibility, Supercapacitor

\section{Introduction}

Recently, renewable energy forms such as solar energy and wind power have been attracting much interest due to fossil fuel depletion and environmental pollution concerns associated with global warming and climate change. With the increasing use of renewable energy, it is necessary to develop an energy storage system (ESS) to efficiently use the produced electrical energy. Recently, secondary batteries, such as Li-ion batteries, have been primarily used as ESSs with renewable energy. Supercapacitors, as electrical capacitors, are attractive ESSs that offer the advantages of a high power density and stable cycle life owing to their charge-storage mechanism, compared to secondary Li-ion batteries and conventional capacitors [1-4].

Supercapacitors are classified into three types according to the mechanism of energy storage: electrical double-layer capacitors (EDLCs), pseudocapacitors (PCs), and hybrid supercapacitors (HCs). EDLCs store energy by charge separation at the electrode-electrolyte interface, while PCs store energy through the Faradaic process. [5] HCs can provide high pseudocapacitance, in addition to the high capacitance provided by the electrical double layer at the supporting electrode surface [6]. EDLCs employ various carbon materials such as activated carbon [7], carbon nanotubes [8], carbon nanofibers (CNFs) [9], and 
graphene [10] as electrodes because their large specific surface area provides a high capacity and their electrochemical stability provides a long service life. However, EDLCs employing carbon materials present the disadvantage of a low energy density. PCs use metal oxides such as $\mathrm{RuO}_{2}[11], \mathrm{NiO}[12,13], \mathrm{Co}_{3} \mathrm{O}_{4}[14,15], \mathrm{MnO}_{2}[16,17]$, and conducting polymers [18] as electrode materials. Among the electrode materials, $\mathrm{CO}_{3} \mathrm{O}_{4}$ has been considered promising because of its high theoretical specific capacitance (Cs = 3560 F/g) [19]. However, $\mathrm{CO}_{3} \mathrm{O}_{4}$ exhibits a low charge/discharge rate, low capacity due to its low electroconductivity, and variations in the crystalline structure during the redox process [20].

To overcome the aforementioned drawbacks, studies have focused on hybrid supercapacitors using various metal oxide-loaded materials. [21-23]. Metal oxides were selected as the loading materials owing to their high electroconductivity compared to conducting polymers. Among the methods for fabricating metal oxide-loaded carbon materials, hydrothermal synthesis enables the synthesis of metal oxides at a low temperature and has been used in various applications [22-26]. Metal oxides prepared on carbon materials may be coated entirely on the carbon surface [24] or exist in the form of agglomerates on the carbon surface [25]. Hydrothermal synthesis generates crystals by raising the temperature and pressure of a homogeneous aqueous solution or precursor suspension. [26] To obtain a high specific capacitance through the addition of metal oxides, it is necessary to evenly distribute and grow metal oxides on the surface of carbon materials. The surface properties of the carbon material in the precursor suspension contribute crucially to the morphology of the metal oxide particles in the electrode. Furthermore, the surface characteristics of carbon materials can control the loading conditions of the metal oxide particles and thus affect the performance of supercapacitors (e.g., if the particles are well-loaded). Therefore, in this study, the relationship between the growth of metal oxide nanoparticles and the hydrophilic/hydrophobic characteristics of a CNF support was investigated.

\section{Materials and Methods}

A CNF support was prepared by electrospinning using a $10 \mathrm{wt}$. \% polyacrylonitrile (PAN, MW $\approx 150,000 \mathrm{~g} \cdot \mathrm{mol}^{-1}$, Sigma Aldrich Co.) solution. The prepared PAN solution was filled in a $10 \mathrm{~mL}$ syringe with a capillary tip $(\mathrm{d}=0.5 \mathrm{~mm})$. Electrospinning was performed with a variable high-voltage power supply (SHV30R ConverTech. Co., Korea); the anode of the power supply was clamped to a syringe needle tip, while the cathode was connected to an aluminum foil collector (diameter $=90$ $\mathrm{mm}$ ). The applied voltage was $20 \mathrm{kV}$, the distance between the nozzle and collector was $18 \mathrm{~cm}$, and the supply rate of the solution was $0.8 \mathrm{~mL} / \mathrm{h}$. The collected electrospun fibers were stabilized at $523 \mathrm{~K}$ for $1 \mathrm{~h}$, carbonized at $1073 \mathrm{~K}$ for $2 \mathrm{~h}$ in $\mathrm{N}_{2}$, and then activated at $1073 \mathrm{~K}$ for $2 \mathrm{~h}$ in $\mathrm{CO}_{2}$. CNFs with FeN@GnP (CNF-FeN@GnP) were also prepared by electrospinning. The solution consisted of $0.009 \mathrm{~g}$ FeN@GnP powder with 10 wt. \% PAN solution, and was sufficiently dispersed using a sonicator. The experimental protocol thereafter was the same as that used for preparing the CNFs.

$\mathrm{Co}_{3} \mathrm{O}_{4}$ nanoparticles were loaded by hydrothermal synthesis using the prepared nanofiber support. The hydrothermal reaction solution was prepared by adding cobalt(II) nitrate hexahydrate $\left(\mathrm{Co}\left(\mathrm{NO}_{3}\right)_{2} \cdot 6 \mathrm{H}_{2} \mathrm{O}, 97 \%\right.$, Samchun Pure Chemical Co., Ltd.) and urea $\left(\mathrm{NH}_{2} \mathrm{CONH}_{2}, 98 \%\right.$, Sigma Aldrich Co.) to $80 \mathrm{~mL}$ of distilled water. The precursors and urea were mixed in a molar ratio of 3:0.5, followed by continuous stirring for $10 \mathrm{~min}$. When the solute was completely dissolved, $0.1 \mathrm{~g}$ of the prepared nanofibers was added and stirred for $10 \mathrm{~min}$. The solution was transferred to a Teflon-lined autoclave and heated at $393 \mathrm{~K}$ for $12 \mathrm{~h}$, following which the autoclave was cooled to room temperature. $\mathrm{Co}_{3} \mathrm{O}_{4} / \mathrm{CNF}$ and $\mathrm{CO}_{3} \mathrm{O}_{4} / \mathrm{CNF}-\mathrm{FeN} @ \mathrm{GnP}$ were obtained after repeated washing with distilled water and drying at $353 \mathrm{~K}$ in a vacuum oven.

Morphological observations and analysis of the elemental compositions of CNF, CNF-FeN@GnP, $\mathrm{CO}_{3} \mathrm{O}_{4} / \mathrm{CNF}$, and $\mathrm{Co}_{3} \mathrm{O}_{4} / \mathrm{CNF}-\mathrm{FeN} @ \mathrm{GnP}$ were performed by field-emission scanning electron microscopy (FE-SEM, Hitachi, S-4800, Japan). Structural characterization of the prepared sample was carried out via X-ray diffraction (XRD) using a 
MiniFlex 600 (Rigaku, Japan) diffractometer with Cu-K $\alpha$ radiation $(\lambda=1.5406 \AA)$ in the $2 \theta$ range of $20^{\circ}-80^{\circ}$ at $4^{\circ} / \mathrm{min}$. The specific surface areas and pore size distributions were determined by applying the Brunauer-Emmett-Teller (BET) equation to the isotherms recorded at $77 \mathrm{~K}$ (BELSORP-mini II, Mictrotrac BEL, USA). The weight change and thermal stability of the prepared samples were estimated by thermogravimetric analysis (TGA, PerkinElmer, TGA8000, USA). Chemical structures, such as functional groups, were examined using Fourier-transform infrared (FT-IR) spectroscopy (Spectrum Two, PerkinElmer, USA). The hydrophobic/hydrophilic properties were identified by contact angle measurements (Smart Drop, Femtobiomed, Korea).

Electrochemical measurements were performed using a battery testing system (BCS815 , Bio-logic, Germany). The area of each electrode was approximately $1 \mathrm{~cm}^{2}$, and a $6 \mathrm{M}$ $\mathrm{KOH}$ aqueous solution was used as the electrolyte. The electrode material was fabricated by mixing $80 \mathrm{wt} . \%$ of the active material, $10 \mathrm{wt} . \%$ of the binder (PVDF), and $10 \mathrm{wt} . \%$ of Super-P as a conductive carbon material, using N-methyl-2-pyrrolidone as the solvent, to yield a slurry. The slurry was pressed onto nickel foil as a current collector and dried at $373 \mathrm{~K}$ for $24 \mathrm{~h}$. The GCD-specific capacitance was calculated using the following formula: In the above formula, $\mathrm{C}\left(\mathrm{F} \bullet \mathrm{g}^{-1}\right)$ denotes the specific capacitance, $\Delta \mathrm{t}$ (s) represents the discharge time, $\mathrm{I}(\mathrm{mA})$ is the discharge current, $\Delta \mathrm{V}(\mathrm{V})$ refers to the voltage, and $\mathrm{m}(\mathrm{mg})$ indicates the mass of the electrode material.

\section{Results and Discussion}

$$
\mathrm{C}=(\mathrm{I} \bullet \Delta \mathrm{t}) /(\mathrm{m} \bullet \Delta \mathrm{V})
$$

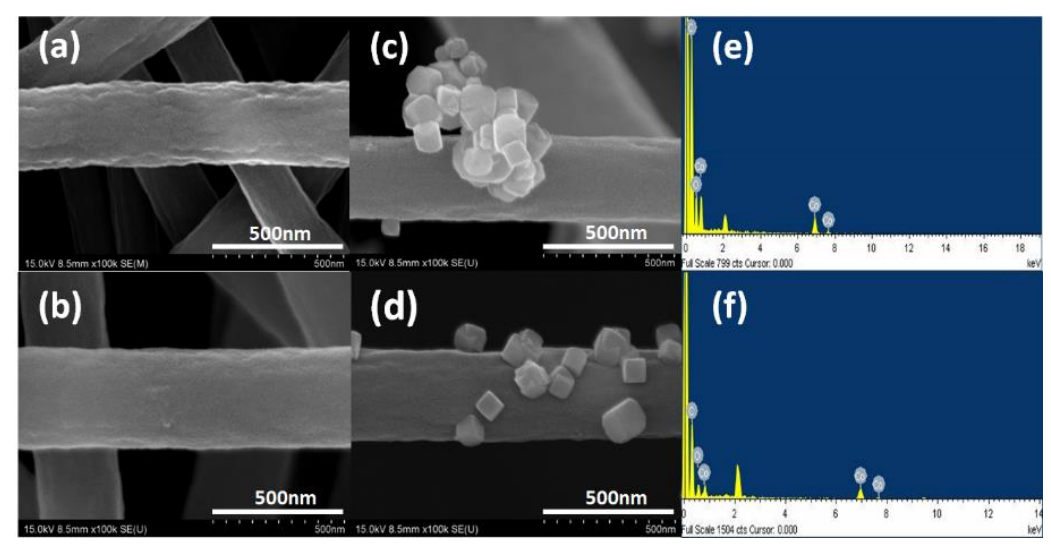

Figure 1. FE-SEM image of (a) CNF (b) CNF-FeN@GnP (c) $\mathrm{Co}_{3} \mathrm{O}_{4} / \mathrm{CNF}$ (d) $\mathrm{Co}_{3} \mathrm{O}_{4} / \mathrm{CNF}-\mathrm{FeN} @ \mathrm{GnP}$ and SEM-EDS analysis of (e) $\mathrm{Co}_{3} \mathrm{O}_{4} / \mathrm{CNF}$ (f) $\mathrm{Co}_{3} \mathrm{O}_{4} / \mathrm{CNF}-\mathrm{FeN} @ \mathrm{GnP}$

Fig. $1(\mathrm{a}, \mathrm{c})$ shows SEM images of the electrospun fibers after calcination at 1073 $\mathrm{K}$ in $\mathrm{CO}_{2}$. The surface morphologies of the CNF and CNF-FeN@GnP nanofibers were rough due to the partial burn-off caused by the reaction between carbon and $\mathrm{CO}_{2}$ during activation [27]. The surface of the CNF-FeN@GnP nanofiber was rougher than that of the CNFs because the FeN@GnP particles that were distributed on the nanofiber surface allowed less heat shrinkage during heat treatment [28]. The average diameters of the CNF and CNF-FeN@GnP nanofibers were approximately $333 \mathrm{~nm}$ and $350 \mathrm{~nm}$, respectively. As an electrode material, a one-dimensional nanofiber is perceived to facilitate short pathways for electron transport in electrochemical reactions [29]. After hydrothermal synthesis in the cobalt solution, the morphology was maintained in the form of a fibrous framework, as shown in Fig. 1 (b, d), which confirmed that $\mathrm{CO}_{3} \mathrm{O}_{4}$ nanoparticles were loaded on the nanofiber support. Loading metal oxides such as $\mathrm{Co}_{3} \mathrm{O}_{4}$ can be effective in enhancing the performance of the supercapacitor because metal oxides are more redox-active than CNFs [30]. In addition, unlike in the CNF/FeN@GnP nanofiber support, agglomeration of the $\mathrm{Co}_{3} \mathrm{O}_{4}$ nanoparticles on the $\mathrm{CNF}$ support was detected after hydrothermal synthesis. To confirm the reason for the same, the hydrophobic/hydrophilic properties of the 
nanofiber support were analyzed by contact angle measurements, the results of which are shown in Fig. 3. To further investigate the elemental composition of the nanoparticles, Energy-dispersive $\mathrm{X}$-ray spectroscopy (EDS) was conducted on $\mathrm{CO}_{3} \mathrm{O}_{4} / \mathrm{CNF}$ and $\mathrm{Co}_{3} \mathrm{O}_{4} / \mathrm{CNF}-\mathrm{FeN} @ \mathrm{GnP}$, and the micrographs are shown in Fig. 1 (e, f). The nanoparticles were determined to contain $\mathrm{Co}$ and $\mathrm{O}$, confirming that $\mathrm{CO}_{3} \mathrm{O}_{4}$ was loaded on the nanofiber support.

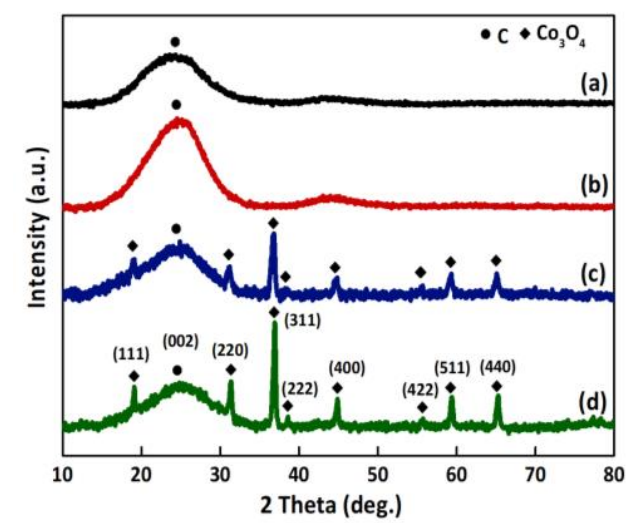

Figure 2. X-ray diffraction (XRD) patterns of (a) CNF (b) CNF-FeN@GnP (c) $\mathrm{Co}_{3} \mathrm{O}_{4} / \mathrm{CNF}$ (d) $\mathrm{CO}_{3} \mathrm{O}_{4} / \mathrm{CNF}-\mathrm{FeN} @ \mathrm{GnP}$.

The crystallinity of CNF, CNF/FeN@GnP, $\mathrm{Co}_{3} \mathrm{O}_{4} / \mathrm{CNF}$, and $\mathrm{Co}_{3} \mathrm{O}_{4} / \mathrm{CNF}-\mathrm{FeN} @ \mathrm{GnP}$ was analyzed by XRD, and the results are shown in Fig. 2. The presence of the (002) peak in the $2 \theta$ range of $20^{\circ}-30^{\circ}$ in the XRD patterns of Fig. $2(a, b)$ indicates the existence of amorphous carbon. After hydrothermal synthesis, the intensity of the peak corresponding to amorphous carbon decreases owing to the relatively high crystallinity of $\mathrm{Co}_{3} \mathrm{O}_{4}$ loaded on the nanofiber support. The results confirm that the prepared $\mathrm{Co}_{3} \mathrm{O}_{4} / \mathrm{CNF}$ and $\mathrm{Co}_{3} \mathrm{O}_{4} / \mathrm{CNF}-\mathrm{FeN} @ \mathrm{GnP}$ are well-developed into $\mathrm{Co}_{3} \mathrm{O}_{4}$ (JCPDS No. 42-1467) crystalline structures, as shown in Fig. 2 (c, d), corresponding to $\mathrm{Co}_{3} \mathrm{O}_{4}$ phases with the (111), (220), (311), (222), (400), (422), (511), and (440) planes. In addition, $\mathrm{Co}_{3} \mathrm{O}_{4}$ does not exhibit any additional peak corresponding to any impurity or secondary phase. The presence of a $\mathrm{Co}_{3} \mathrm{O}_{4}$ peak in the XRD pattern confirms that the nanoparticles loaded on the nanofiber support are those of $\mathrm{CO}_{3} \mathrm{O}_{4}$, as also corroborated by the SEM-EDS results. These results prove that $\mathrm{CO}_{3} \mathrm{O}_{4} / \mathrm{CNF}$ and $\mathrm{Co}_{3} \mathrm{O}_{4} / \mathrm{CNF}-\mathrm{FeN} @ \mathrm{GnP}$ were successfully prepared after hydrothermal synthesis [24].

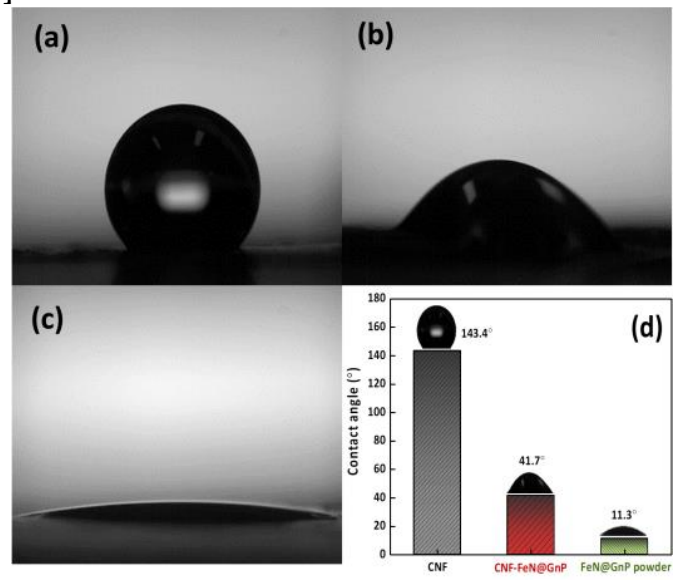

Figure 3. Contact angle image of (a) CNF (b) CNF-FeN@GnP (c) FeN@GnP powder (d) comparison graph of contact angle.

The contact angle results for CNF and the CNF/FeN@GnP nanofiber support powders are shown in Fig. $3(\mathrm{a}, \mathrm{b})$. To determine whether the surface was hydrophobic (contact angle higher than $90^{\circ}$ ) or hydrophilic (contact angle lower than $90^{\circ}$ ), contact angle 
measurements were conducted using water. The CNF support showed hydrophobic properties with a contact angle of $143.4^{\circ}$, while CNF/FeN@GnP showed hydrophilic properties with a contact angle of $41.7^{\circ}$. The contact angle of FeN@GnP powder was also measured to determine the hydrophilicity of CNF/FeN@GnP (Fig. 3 (c)). As shown in Fig. 3 (d), FeN@GnP powder had hydrophilic properties with a contact angle of $11.3^{\circ}$. Ju et al. reported that when carbon composite fibers were prepared by electrospinning a polymer solution containing graphene nanoplates, the nanoplates were distributed on the surface of the fibers by the centrifugal force generated during electrospinning [29]. Hence, it is expected that the properties of the CNF surface will be affected by the added FeN@GnP powder. Cheng et al. and $\mathrm{Lu}$ et al. reported that hydrophobic surface properties induce high agglomeration due to the strong hydrophobic interaction between particles [31, 32]. Therefore, compared to the hydrophilic FeN@GnP nanofiber support, the hydrophobic $\mathrm{CNF}$ support can enhance the aggregation of $\mathrm{Co}_{3} \mathrm{O}_{4}$ nanoparticles loaded on the surface of the nanofiber support, consistent with the SEM results.

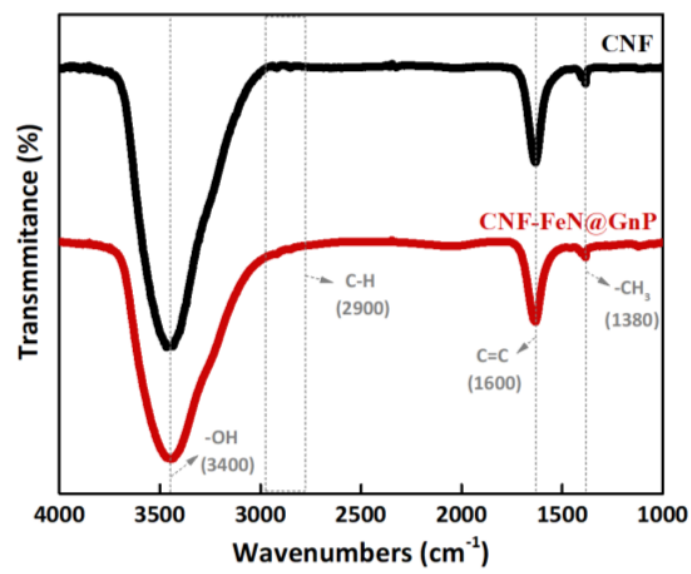

Figure 4. Fourier transform infrared spectroscopy (FT-IR) spectra of CNF and CNF-FeN@GnP.

To further identify the hydrophobic/hydrophilic surface properties of CNF and the CNF-FeN@GnP nanofiber supports, the functional groups were determined by FT-IR spectroscopy. Fig. 4 shows that CNF and CNF/FeN@GnP possess functional groups such as $-\mathrm{OH}\left(3400 \mathrm{~cm}^{-1}\right), \mathrm{C}-\mathrm{H}\left(2900 \mathrm{~cm}^{-1}\right), \mathrm{C}=\mathrm{C}\left(1600 \mathrm{~cm}^{-1}\right)$, and $-\mathrm{CH}_{3}\left(1380 \mathrm{~cm}^{-1}\right)$. The FT-IR peak intensities of CNF and CNF/FeN@GnP were difficult to confirm in the FT-IR spectra because a small amount $(0.009 \mathrm{~g})$ of FeN@GnP powder was added to the CNFs. However, the peak intensities of the $-\mathrm{CH}$ and $-\mathrm{CH}_{3}$ groups of the CNFs were slightly higher than those of CNF/FeN@GnP. The integral values of the peak $\left(-\mathrm{CH}_{3}\right) /(\mathrm{C}=\mathrm{C})$ for $\mathrm{CNFs}$ and $\mathrm{CNF} / \mathrm{FeN} @ \mathrm{GnP}$ were 0.044 and 0.042 , respectively. Zhu et al. reported that $-\mathrm{CH}$ [33] and $\mathrm{CH}_{3}$ groups [34] in the FT-IR spectra induce hydrophobic properties. Therefore, these results confirmed that the CNF support has hydrophobic properties, making the FT-IR results consistent with the contact angle measurements.
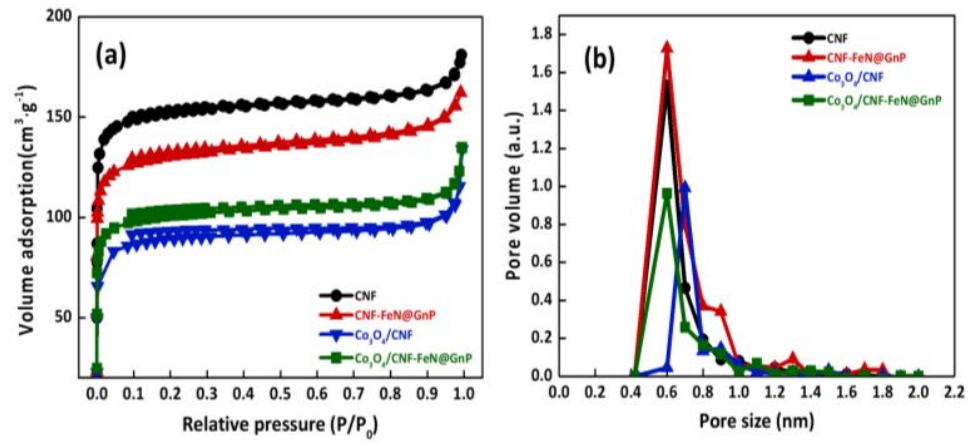

Figure 5. (a) Nitrogen adsorption-desorption isotherms and (b) pore distribution of CNF, CNF$\mathrm{FeN} @ \mathrm{GnP}, \mathrm{Co}_{3} \mathrm{O}_{4} / \mathrm{CNF}$, and $\mathrm{Co}_{3} \mathrm{O}_{4} / \mathrm{CNF}-\mathrm{FeN} @ \mathrm{GnP}$. 
Fig. 5 shows the nitrogen adsorption/desorption isotherms of CNF, CNF/FeN@GnP, $\mathrm{Co}_{3} \mathrm{O}_{4} / \mathrm{CNF}$, and $\mathrm{CO}_{3} \mathrm{O}_{4} / \mathrm{CNF}-\mathrm{FeN} @ \mathrm{GnP}$. The isotherms are typical type I, indicating the existence of well-developed micropores in the samples, as shown in Fig. 5 (a). The specific surface areas of $\mathrm{CNF}, \mathrm{CNF} / \mathrm{FeN} @ \mathrm{GnP}, \mathrm{Co}_{3} \mathrm{O}_{4} / \mathrm{CNF}$, and $\mathrm{Co}_{3} \mathrm{O}_{4} / \mathrm{CNF}-\mathrm{FeN} @ \mathrm{GnP}$ were $598.25,509.38,342.98$, and $391.88 \mathrm{~m}^{2} / \mathrm{g}$, respectively. The specific surface areas of CNF and the CNF/FeN@GnP nanofibers were similar. CNF/FeN@GnP had a slightly lower specific surface area than the CNFs because FeN@GnP was partially embedded in the CNFs and provides a slightly less rough nanofiber surface of FeN@GnP. In addition, the pore volumes of $\mathrm{CNF}, \mathrm{CNF} / \mathrm{FeN} @ \mathrm{GnP}, \mathrm{Co}_{3} \mathrm{O}_{4} / \mathrm{CNF}$, and $\mathrm{Co}_{3} \mathrm{O}_{4} / \mathrm{CNF}-\mathrm{FeN} @ \mathrm{GnP}$ were 0.2757 , $0.2499,0.1883$, and $0.1966 \mathrm{~cm}^{3} / \mathrm{g}$, respectively, as shown in Fig. 5 (b). The smaller pore volume of CNF/FeN@GnP compared to that of the CNFs can additionally confirm the effect of FeN@GnP powder on the specific surface area. In addition, the specific surface area decreased after loading $\mathrm{Co}_{3} \mathrm{O}_{4}$ nanoparticles onto $\mathrm{CNF}$ and the $\mathrm{CNF} / \mathrm{FeN} @ \mathrm{GnP}$ nanofiber supports because the loaded nanoparticles induced a decrease in the pore volume of the nanofiber. These results were confirmed by a decrease in the pore volume intensity, as shown in Fig. 5 (b).

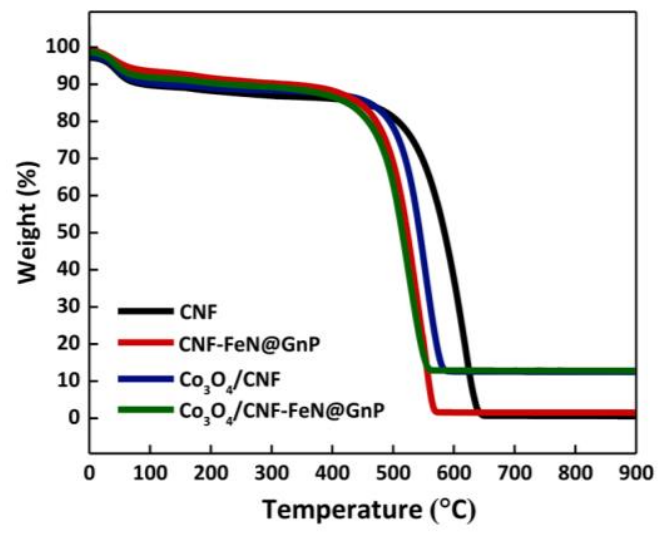

Figure 6. Thermogravimetric analysis (TGA) curves of CNF, CNF-FeN@GnP, $\mathrm{Co}_{3} \mathrm{O}_{4} / \mathrm{CNF}$, and $\mathrm{CO}_{3} \mathrm{O}_{4} / \mathrm{CNF}-\mathrm{FeN} @ \mathrm{GnP}$.

Fig. 6 shows the TGA curves of CNF, CNF-FeN@GnP, $\mathrm{Co}_{3} \mathrm{O}_{4} / \mathrm{CNF}$, and $\mathrm{Co}_{3} \mathrm{O}_{4} / \mathrm{CNF}-$ FeN@GnP in air. Overall, the nanofibers show a weight-loss stage of approximately $10 \%$ up to $273-373 \mathrm{~K}$. This weight loss corresponds to the evaporation of water and the solvent. Significant weight loss occurs between 723 and $873 \mathrm{~K}$. The second weight loss is attributed to the low thermal stability of the $\mathrm{CNFs}$. The loaded content of $\mathrm{Co}_{3} \mathrm{O}_{4}$ was predicted from the residual content after burning out the weight lost by PAN and the FeN@GnP-embedded PAN fiber composite in the air. The residual contents of CNF, CNF-FeN@GnP, $\mathrm{Co}_{3} \mathrm{O}_{4} / \mathrm{CNF}$, and $\mathrm{Co}_{3} \mathrm{O}_{4} / \mathrm{CNF}-\mathrm{FeN} @ \mathrm{GnP}$ were $0.5,1.5,12.5$, and 12.8 , respectively. The higher weights of $\mathrm{Co}_{3} \mathrm{O}_{4} / \mathrm{CNF}$ and $\mathrm{Co}_{3} \mathrm{O}_{4} / \mathrm{CNF}-\mathrm{FeN} @ \mathrm{GnP}$ compared to those of $\mathrm{CNF}$ and CNF-FeN@GnP in the TGA curve indicated that similar $\mathrm{Co}_{3} \mathrm{O}_{4}$ nanoparticles were wellloaded on CNFs and CNF/FeN@GnP. In comparison to CNFs, the CNF-FeN@GnP nanofibers were confirmed to have undergone a rapid weight loss. In addition, after loading $\mathrm{CO}_{3} \mathrm{O}_{4}$ nanoparticles on the nanofiber support, weight loss occurred faster at a lower temperature than that in the pristine nanofiber supports, as shown in the TGA curves (Fig. 6). It is assumed that the interaction of the surface of the nanofibers may be affected by the loaded $\mathrm{C}_{3} \mathrm{O}_{4}$ nanoparticles or Fe in FeN@GnP. Oh et al. reported that the carbon around metal particles is easily decomposed by the chemical catalytic effect of the metal particles at high temperatures [35]. The faster weight loss originates from the chemical decomposition of carbon during burn-off by Fe in FeN@GnP or loaded $\mathrm{Co}_{3} \mathrm{O}_{4}$. 

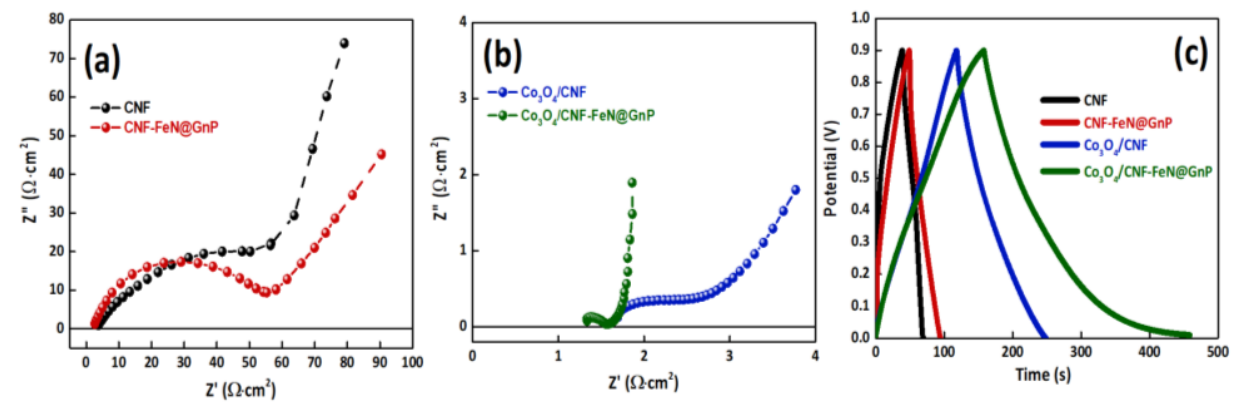

Figure 7. Nyquist plot of (a) CNF and CNF-FeN@GnP, (b) $\mathrm{Co}_{3} \mathrm{O}_{4} / \mathrm{CNF}$ and $\mathrm{Co}_{3} \mathrm{O}_{4} / \mathrm{CNF}-\mathrm{FeN} @ \mathrm{GnP}$ and (c) galvanostatic charge discharge (GCD) curve of CNF, CNF-FeN@GnP, $\mathrm{Co}_{3} \mathrm{O}_{4} / \mathrm{CNF}$, and $\mathrm{Co}_{3} \mathrm{O}_{4} / \mathrm{CNF}-\mathrm{FeN} @ \mathrm{GnP}$.

Fig. 7 (a) shows typical Nyquist plots of the CNF and CNF-FeN@GnP samples measured under open-circuit conditions. The polarization resistance of CNF/FeN@GnP was evaluated to be approximately $62.9 \Omega$, which is much lower than that of the CNFs (73.9 $\Omega$ ). A lower polarization resistance leads to improved conductivity [36] and faster charge transport owing to the redox properties of FeN@GnP. Fig. 7 (b) shows Nyquist plots of $\mathrm{Co}_{3} \mathrm{O}_{4} / \mathrm{CNF}(1.49 \Omega)$ and $\mathrm{Co}_{3} \mathrm{O}_{4} / \mathrm{CNF}-\mathrm{FeN} @ \mathrm{GnP}(0.2 \Omega)$. $\mathrm{Co}_{3} \mathrm{O}_{4}$ loading on each nanofiber support resulted in a lower polarization resistance compared to those of other nanofiber supports. $\mathrm{Co}_{3} \mathrm{O}_{4}$ loading increases the electroconductivity through the redox reaction of metal oxides and can improve the performance of the supercapacitor [37]. In the GCD curve (Fig. 7 (c)), $\mathrm{Co}_{3} \mathrm{O}_{4} / \mathrm{CNF}-\mathrm{FeN} @ \mathrm{GnP}$ shows an excellent specific capacitance of $668 \mathrm{~F} / \mathrm{g}$ compared to those of the other samples (CNF, CNF-FeN@GnP, $\mathrm{Co}_{3} \mathrm{O}_{4} / \mathrm{CNF}$ have capacitances of 71, 102, and $291.1 \mathrm{~F} / \mathrm{g}$, respectively). The $\mathrm{Co}_{3} \mathrm{O}_{4} / \mathrm{CNF}$ and $\mathrm{Co}_{3} \mathrm{O}_{4} / \mathrm{CNF}-\mathrm{FeN} @ \mathrm{GnP}$ nanofibers show different results despite being loaded with $\mathrm{Co}_{3} \mathrm{O}_{4}$. This is because the nanoparticles are more evenly dispersed and grown on the surface of the $\mathrm{Co}_{3} \mathrm{O}_{4} / \mathrm{CNF}$ FeN@GnP nanofibers because of the hydrophilic properties of the CNF/FeN@GnP nanofiber support. The loading amount of $\mathrm{C}_{3} \mathrm{O}_{4}$ particles was confirmed to be similar in TGA, but it is obvious that the dispersion and agglomeration of $\mathrm{Co}_{3} \mathrm{O}_{4}$ particles affected the difference in the performance. Therefore, this study reveals the dependence of the dispersibility of the loaded nanoparticles on the hydrophobic/hydrophilic surface properties of nanofibers for advanced supercapacitor materials.

\section{Conclusions}

In this study, a composite electrode material was prepared using a two-step process. Two types of nanofiber samples, CNFs and CNF-FeN@GnP nanofibers, were prepared by electrospinning, following which $\mathrm{CO}_{3} \mathrm{O}_{4}$ nanoparticles were loaded onto the nanofiber support via hydrothermal synthesis. Depending on the hydrophilicity and hydrophobicity of the two types of nanofibers, there was a difference in the dispersibility when loading the nanoparticles onto the nanofibers. CNF-FeN@GnP with hydrophilic surface properties enabled the even loading of $\mathrm{Co}_{3} \mathrm{O}_{4}$ nanoparticles on the surface of the nanofiber support compared to CNFs. The prepared $\mathrm{Co}_{3} \mathrm{O}_{4} / \mathrm{CNF}-\mathrm{FeN} @ \mathrm{GnP}$ nanofiber exhibited an excellent capacitance of $668 \mathrm{~F} / \mathrm{g}$ owing to the high redox characteristics of evenly dispersed $\mathrm{CO}_{3} \mathrm{O}_{4}$ nanoparticles. Thus, the results proved that the dispersibility of the loaded nanoparticles and its dependence on the hydrophobic/hydrophilic surface properties of the nanofibers are crucial for determining the usefulness of the prepared materials as electrodes.

Author Contributions: conceptualization, J.Y. and Y.W.; investigation, H.Y. and S.L.; data curation, H.Y. and S.Y.; writing - original draft preparation, H.Y.; writing - review and editing, J.Y. and Y.W.; visualization, H.Y.; supervision, I.J., J.Y. and Y.W. 
Funding: This research was supported by the Mid-career Researcher Program (NRF2020R1A2C1007847) and the Basic Research Laboratory Program (No. NRF2020R1A4A3079200) through the National Research Foundation of Korea, funded by the Korea government Ministry of Education.

Conflicts of Interest: The authors declare no conflict of interest.

\section{References}

1. Conway, B. E., Electrochemical Supercapacitors. Kluwer-Plenum Publishing Co, New York 1999, 1-698.

2. Simon, P.; Gogotsi, Y., Materials for electrochemical capacitors. Nanoscience and technology: a collection of reviews from Nature journals 2010, 320-329.

3. Yan, J.; Wang, Q.; Wei, T.; Fan, Z., Recent advances in design and fabrication of electrochemical supercapacitors with high energy densities. Advanced Energy Materials 2014, 4, (4), 1300816.

4. Shao, Y.; El-Kady, M. F.; Wang, L. J.; Zhang, Q.; Li, Y.; Wang, H.; Mousavi, M. F.; Kaner, R. B., Graphene-based materials for flexible supercapacitors. Chemical Society Reviews 2015, 44, (11), 3639-3665.

5. Halper, M. S.; Ellenbogen, J. C., Supercapacitors: A brief overview. The MITRE Corporation, McLean, Virginia, USA 2006, 1.

6. Zhao, X.; Johnston, C.; Grant, P. S., A novel hybrid supercapacitor with a carbon nanotube cathode and an iron oxide/carbon nanotube composite anode. Journal of Materials Chemistry 2009, 19, (46), 8755-8760.

7. Ishimoto, S.; Asakawa, Y.; Shinya, M.; Naoi, K., Degradation responses of activated-carbon-based EDLCs for higher voltage operation and their factors. Journal of the Electrochemical Society 2009, 156, (7), A563.

8. Signorelli, R.; Ku, D. C.; Kassakian, J. G.; Schindall, J. E., Electrochemical double-layer capacitors using carbon nanotube electrode structures. Proceedings of the IEEE 2009, 97, (11), 1837-1847.

9. Kim, B.-H.; Yang, K. S.; Ferraris, J. P., Highly conductive, mesoporous carbon nanofiber web as electrode material for highperformance supercapacitors. Electrochimica Acta 2012, 75, 325-331.

10. Miller, J. R.; Outlaw, R.; Holloway, B., Graphene electric double layer capacitor with ultra-high-power performance. Electrochimica Acta 2011, 56, (28), 10443-10449.

11. Kakaei, K.; Esrafili, M. D.; Ehsani, A., Alcohol oxidation and hydrogen evolution. In Interface Science and Technology 2019, 27, 253-301.

12. Lee, J. Y.; Liang, K.; An, K. H.; Lee, Y. H., Nickel oxide/carbon nanotubes nanocomposite for electrochemical capacitance. Synthetic metals 2005, 150, (2), 153-157.

13. Yuan, C.; Zhang, X.; Wu, Q.; Gao, B., Effect of temperature on the hybrid supercapacitor based on $\mathrm{NiO}$ and activated carbon with alkaline polymer gel electrolyte. Solid State Ionics 2006, 177, (13-14), 1237-1242.

14. Meher, S. K.; Rao, G. R., Ultralayered $\mathrm{C}_{3} \mathrm{O}_{4}$ for high-performance supercapacitor applications. The Journal of Physical Chemistry C 2011, 115, (31), 15646-15654.

15. Xia, X.-h.; Tu, J.-p.; Mai, Y.-j;; Wang, X.-l.; Gu, C.-d.; Zhao, X.-b., Self-supported hydrothermal synthesized hollow $\mathrm{Co}_{3} \mathrm{O}_{4}$ nanowire arrays with high supercapacitor capacitance. Journal of Materials Chemistry 2011, 21, (25), 9319-9325.

16. Chang, J.-K.; Chen, Y.-L.; Tsai, W.-T., Effect of heat treatment on material characteristics and pseudo-capacitive properties of manganese oxide prepared by anodic deposition. Journal of power sources 2004, 135, (1-2), 344-353.

17. Prasad, K. R.; Miura, N., Potentiodynamically deposited nanostructured manganese dioxide as electrode material for electrochemical redox supercapacitors. Journal of Power Sources 2004, 135, (1-2), 354-360.

18. Hou, Y.; Chen, L.; Zhang, L.; Kang, J.; Fujita, T.; Jiang, J.; Chen, M., Ultrahigh capacitance of nanoporous metal enhanced conductive polymer pseudocapacitors. Journal of power sources 2013, 225, 304-310.

19. Yang, S.; Liu, Y.; Hao, Y.; Yang, X.; Goddard III, W. A.; Zhang, X. L.; Cao, B., Oxygen-vacancy abundant ultrafine $\mathrm{Co}_{3} \mathrm{O}_{4} / \mathrm{gra}_{-}$ phene composites for high-rate supercapacitor electrodes. Advanced Science 2018, 5, (4), 1700659.

20. Zhang, Y.; Hu, Y.; Wang, Z.; Lin, T.; Zhu, X.; Luo, B.; Hu, H.; Xing, W.; Yan, Z.; Wang, L., Lithiation-Induced Vacancy Engineering of $\mathrm{Co}_{3} \mathrm{O}_{4}$ with Improved Faradic Reactivity for High-Performance Supercapacitor. Advanced Functional Materials 2020, 30, (39), 2004172.

21. Rakhi, R.; Alshareef, H. N., Enhancement of the energy storage properties of supercapacitors using graphene nanosheets dispersed with metal oxide-loaded carbon nanotubes. Journal of Power Sources 2011, 196, (20), 8858-8865.

22. Zawadzki, M.; Wrzyszcz, J., Hydrothermal synthesis of nanoporous zinc aluminate with high surface area. Materials research bulletin 2000, 35, (1), 109-114.

23. Stein, A.; Keller, S. W.; Mallouk, T. E., Turning down the heat: Design and mechanism in solid-state synthesis. Science 1993, 259, (5101), 1558-1564.

24. Lu, F.; Wang, J.; Sun, X.; Chang, Z., 3D hierarchical carbon nanofibers/TiO2@ MoS2 core-shell heterostructures by electrospinning, hydrothermal and in-situ growth for flexible electrode materials. Materials \& Design 2020, 189, 108503.

25. Mao, K.; Wu, X.; Min, X.; Huang, Z.; Liu, Y.-g.; Fang, M., New efficient visible-light-driven photocatalyst of chitin-modified titanium dioxide/carbon fiber composites for wastewater. Scientific reports 2019, 9, (1), 1-9.

26. Laudise, R.; Nielsen, J., Hydrothermal crystal growth. In Solid State Physics, Elsevier 1961, 12, 149-222.

27. Zhou, X.; $\mathrm{Yi}, \mathrm{H}$.; Tang, X.; Deng, $\mathrm{H}$.; Liu, $\mathrm{H}$., Thermodynamics for the adsorption of $\mathrm{SO}_{2}, \mathrm{NO}$ and $\mathrm{CO}_{2}$ from flue gas on activatecarbon fiber. Chemical Engineering Journal 2012, 200, 399-404. 
28. Ju, Y. W.; Yoo, S.; Kim, C.; Kim, S.; Jeon, I. Y.; Shin, J.; Baek, J. B.; Kim, G., Fe@ N-Graphene Nanoplatelet-Embedded Carbon Nanofibers as Efficient Electrocatalysts for Oxygen Reduction Reaction. Advanced science 2016, 3, (1), 1500205.

29. Ouyang, T.; Cheng, K.; Yang, F.; Zhou, L.; Zhu, K.; Ye, K.; Wang, G.; Cao, D., From biomass with irregular structures to 1D carbon nanobelts: a stripping and cutting strategy to fabricate high performance supercapacitor materials. Journal of Materials Chemistry A 2017, 5, (28), 14551-14561.

30. Yang, P.; Chen, Y.; Yu, X.; Qiang, P.; Wang, K.; Cai, X.; Tan, S.; Liu, P.; Song, J.; Mai, W., Reciprocal alternate deposition strategy using metal oxide/carbon nanotube for positive and negative electrodes of high-performance supercapacitors. Nano Energy 2014, 10, 108-116.

31. Cheng, W.; Deng, Z.; Tong, X.; Lu, T., Hydrophobic agglomeration of fine pyrite particles induced by flotation reagents. Minerals 2020, 10, (9), 801.

32. Lu, S.; Song, S., Hydrophobic interaction in flocculation and flotation 1. Hydrophobic flocculation of fine mineral particles in aqueous solution. Colloids and surfaces 1991, 57, (1), 49-60.

33. Zhu, Y.; Otsubo, M.; Honda, C., Degradation of polymeric materials exposed to corona discharges. Polymer testing 2006, 25, (3), 313-317.

34. Zhu, Y.; Otsubo, M.; Honda, C.; Tanaka, S., Loss and recovery in hydrophobicity of silicone rubber exposed to corona discharge. Polymer degradation and stability 2006, 91, (7), 1448-1454.

35. Oh, G.-Y.; Ju, Y.-W.; Jung, H.-R.; Lee, W.-J., Preparation of the novel manganese-embedded PAN-based activated carbon nanofibers by electrospinning and their toluene adsorption. Journal of Analytical and Applied Pyrolysis 2008, 81, (2), 211-217. 37.

36. Jiang, R.; Huang, T.; Tang, Y.; Liu, J.; Xue, L.; Zhuang, J.; Yu, A., Factors influencing $\mathrm{MnO}_{2} / \mathrm{multi}_{\text {-walled carbon nanotubes }}$ composite's electrochemical performance as supercapacitor electrode. Electrochimica acta 2009, 54, (27), 7173-7179.

37. Xiang, K.; Xu, Z.; Qu, T.; Tian, Z.; Zhang, Y.; Wang, Y.; Xie, M.; Guo, X.; Ding, W.; Guo, X., Two dimensional oxygen-vacancyrich $\mathrm{Co}_{3} \mathrm{O}_{4}$ nanosheets with excellent supercapacitor performances. Chemical Communications 2017, 53, (92), $12410-12413$. 